\title{
A planificação em creche: evidências da prática (Portugal)
}

Resumo: Este trabalho foi realizado no âmbito do Grupo Projeto Creche (Instituto Politécnico de Leiria/Escola Superior de Educação e Ciências Sociais - Portugal) e visa dar a conhecer a estrutura e os objetivos formulados em seis planificações efetuadas por três Educadoras Infantis a trabalhar em contexto de Creche, no ano letivo 2012/2013, em Portugal. Socorrendo-se da análise documental, este estudo descritivo revelou que as planificações analisadas se apresentam organizadas em grelha e com objetivos formulados de acordo com os referenciais para a Educação Pré-Escolar (Ministério da Educação, 1997) ou com os domínios de desenvolvimento da criança pequena (Post \& Hohmann, 2007). Estas evidências assumem-se como importantes referenciais para o estudo da planificação em contexto de Creche.

Palavras-chave: Creche; Educação Infantil; Planificação

Verónica Fonsecal

Edite Rodrigues ${ }^{2}$

Isabel Simões Dias ${ }^{3}$

\section{Planning in daycare: evidences of practice (Por- tugal)}

Abstract: This work was conducted under the Creche Project Group (IPL / School of Education and Social Sciences - Portugal) and aims to make known the structure and formulated goals in six lesson plans made for three Educating Children working in context kindergarten, in school year 2012/2013 in Portugal. Bailing from the documental analysis, this descriptive study revealed that lesson plans analyzed present with formulated goals in accordance with the references for Preschool Education (Ministry of Education, 1997) or the young child development domains (Post \& Hohmann, 2007). These evidences are assumed to be important references for the study of planning in kindergarten context.

Keywords: Daycare; Childhood Education; Planning

\footnotetext{
| Licenciada em Educação de Infância. Educadora de Infância na Associação Bem Estar de Parceiros (Leiria-Portugal). Membro do Núcleo de Investigação e Desenvolvimento em Educação/Grupo Projeto Creche (GPC) do Instituto Politécnico de Leiria/Escola Superior de Educação e Ciências Sociais (Portugal). E-mail:veronicafonsecatrabalho@gmail.com

2 Licenciada em Educação de Infância. Educadora de Infância no Centro Infantil Moinho de Vento (Batalha/Portugal). Membro do Núcleo de Investigação e Desenvolvimento em Educação/Grupo Projeto Creche (GPC) do Instituto Politécnico de Leiria/Escola Superior de Educação e Ciências Sociais (Portugal). E-mail: ed_dorosario@hotmail.com

3 Doutora em Psicologia. Docente no Instituto Politécnico de Leiria/Escola Superior de Educação e Ciências Sociais. Membro do Núcleo de Investigação e Desenvolvimento em Educação/Grupo Projeto Creche (GPC) (Portugal). E-mail: isabel.dias@ipleiria.pt
} 


\section{Introdução}

Este estudo surgiu no âmbito do Grupo Projeto Creche ${ }^{1}$, um espaço de reflexão que fomenta a troca de saberes e que estimulou a dúvida científica acerca da planificação ${ }^{2}$ em contexto de creche. Como estruturar/organizar uma planificação em contexto de creche? Quais os referentes a seguir? Quais os conteúdos a incluir? Partindo de uma reflexão acerca do conceito e das tipologias de planificação, estudámos as abordagens curriculares de High Scope e de ReggioEmilia para equacionar o estudo da planificação enquanto vetor do trabalho pedagógico do Educador Infantil com crianças até aos três anos de idade.

A planificação, conceito fluente no discurso de profissionais da área da educação, pode ser entendida como “....instrumento de controlo da acção do professor ...” (Pacheco, 1990, p.12), como um documento orientador que proporciona segurança ao educador ou como uma previsão de

"(...) possíveis cursos de acção de um fenómeno e plasmar de algum modo as nossas previsões, desejos, aspirações e metas num projecto que seja capaz de representar, dentro do possível, as nossas ideias acerca das razões pelas quais desejaríamos conseguir, e como poderíamos levar a cabo, um plano para as concretizar" (Zabalza, 1992, p.48).

Para Simões (2004), planificar é decidir as estratégias de organização do grupo de crianças para que cada um apreenda o máximo que puder e compreende a avaliação que se deve ajustar ao grupo/contexto educativo.

Neste sentido, planificar é um processo que corresponde a um conjunto de ações pensadas previamente que vão permitir ao profissional colocar em prática as suas intencionalidades educativas. Assim, a planificação é considerada um instrumento que visa otimizar a prática educativa e que exige ao educador que se apoie

“(...) em princípios teóricos (curriculares e pedagógico-didácticos) para, uma vez contextualizados esses princípios, adaptar o seu pensamento às componentes e características fundamentais da acção concreta. É esta a razão, aliás, que justifica a tese de que planificar é "pôr em acção", numa realidade concreta, as crianças com que trabalha, não esquecendo a individualidade de cada um, o pensamento cientifico pedagógico" (Vilar, 1993, p.5)

Em contexto educativo, o profissional planifica para esquematizar/organizar o seu trabalho/ tempo, embora não exista nenhuma forma rígida de o fazer (Dias, 2009). Existem, sim, tipologias

\footnotetext{
I O GrupoProjeto Creche nasceu no ano letivo de 2008/2009 na Escola Superior de Educação e Ciências Sociais - Instituto Politécnico de Leiria (ESECS/IPL), instituição do Ensino Superior Politécnico Português, impulsionado pela necessidade de refletir sobre o trabalho educativo desenvolvido em contexto de creche, com crianças até aos 3 anos de idade. No ano letivo 2012/20।3, a equipa contava com a participação de três docentes da ESECS, uma técnica de educação e onze educadoras de infância que desenvolviam a sua atividade profissional em zonas distintas da Região Centro de Portugal, em instituições públicas, privadas e de solidariedade social.

$2 \quad$ Planificação, em português do Brasil, corresponde ao termo planejamento.
} 
distintas de planificação como, por exemplo, a planificação didática (Zabalza,1992) ou a planificação linear (Freitas, 1995). A planificação didática é entendida como

"(.. .) um conjunto de conhecimentos, ideias ou experiências sobre o fenómeno a organizar, que actuará como apoio conceptual e de justificação do que se decide; um propósito, fim ou meta a alcançar que nos indica a direcção a seguir; uma previsão a respeito do processo a seguir que deverá concretizar-se numa estratégia de procedimentos que inclui os conteúdos ou tarefas a realizar, a sequência das actividades e, de alguma forma, a avaliação ou encerramento do processo" (Zabalza, 1992, p.48).

A planificação linear, carateriza-se pela

"( . . . conotação behaviorista de tais objectivos bem como as preocupações de tecnicismo formal com ela relacionados que reflectem bem a preocupação de tradução universal de todos os objectivos, em termos de comportamentos observáveis" (Freitas, 1995, p.28).

Cada Educador Infantil adota a planificação à sua realidade educativa e ao seu grupo de crianças, preferencialmente sustentando-se na premissa de que deverá haver um ajustamento entre pensamento/ação e entre teoria/prática.

Em Portugal, a Educação Infantil é tutelada pelo Ministério da Solidariedade, Emprego e Segurança Social (Creche) e pelo Ministério da Educação (Educação Pré-Escolar em Jardim de Infância). A creche é considerada uma resposta social que visa responder às necessidades das crianças até aos 3 anos e o jardim-de-infância destina-se a crianças dos 3 aos 6 anos de idade.

Para a Educação Pré-Escolar, o trabalho a desenvolver com as crianças sustenta-se nas Orientações Curriculares (Ministério da Educação, 1997), documento orientador do trabalho do Educador Infantil que organiza os conhecimentos a desenvolver com as crianças em três grandes áreas de conteúdo: Área da Formação Pessoal e Social, Área do Conhecimento do Mundo e Área da Expressão e Comunicação. Neste contexto educativo, estas áreas podem surgir como possíveis indicadores para a elaboração da planificação.

Para as crianças até aos 3 anos, em Portugal, ainda não existe um documento pedagógico orientador do trabalho do Educador Infantil ${ }^{3}$. No entanto, deseja-se que o Educador Infantil que trabalhe em contexto de Creche possua conhecimentos específicos e concretize uma planificação apropriada, sustentada no conhecimento do desenvolvimento e aprendizagem nos primeiros anos de vida (Dias, Correia e Marcelino, 2013; Dias e Correia, 2012) e nas finalidades educativas da Creche (Portugal, 2012). Conforme defende Portugal (1998, p.114),

“(...) o importante em creche é que a ação educativa seja individualizada, respeitando o ritmo individual de

3 O Instituto da Segurança Social, em 20 I 0, publicou o "Manual de Processos-Chave para a Resposta Social da Creche" como instrumento de avaliação da Creche enquanto resposta social. Neste Manual defende-se a elaboração de um Projeto Pedagógico e de um Plano Individual, instrumentos que algumas instituições/educadoras têm entendido como possíveis formas de planificação. 
cada criança, o que implica uma gestão flexível do currículo, ao nível das atividades pedagógicas realizadas neste contexto".

Assim, em Portugal, o educador pode optar pela metodologia de trabalho que deseja desenvolver com as crianças, podendo sustentar a sua proposta de planificação em modelos curriculares validados para o contexto de Creche, como o High Scope ou o Reggio Emilia. Estas propostas didáticas defendem a elaboração de um plano rico em atividades promotoras do desenvolvimento/ aprendizagem das crianças, ideia corroborada por Portugal (1998, p. 204) quando afirma que "se a educação é uma preocupação básica na creche, se o educador educa e não é apenas um guardador de crianças, importa que haja um currículo, isto é, um plano de desenvolvimento e aprendizagem.”

O modelo High Scope defende a aprendizagem ativa das crianças, valorizando a observação da criança, a interação adulto-criança, os horários e as rotinas e o ambiente físico. Para Post e Hohmann (2007), estes vetores da roda da aprendizagem, associados ao trabalho de equipa, aos registos episódicos, às planificações diárias e à relação com a família representam os pilares do trabalho do educador que quer conhecer e responder às necessidades e interesses de cada criança e do grupo. Para Formosinho (1996, p.65),

"(...) a estrutura curricular High Scope está toda pensada para realizar esta grande finalidade piagetiana: a construção da autonomia intelectual da criança. Isto é verdade para a sua filosofia educacional, para a sua concepção de espaço e materiais, para a sua rotina diária e experiência-chave, para a sua concepção do papel do adulto e, finalmente, para o seu triângulo: observação, planificação, avaliação."

O modelo de Reggio Emilia, impulsionado por Loris Malaguzzi, desenvolve-se em torno da construção da imagem da criança. Aqui, a criança é vista como um sujeito de direitos, competente, como um aprendiz ativo que continuamente constrói e testa teorias acerca de si próprio e do mundo que a rodeia. Para esta abordagem, a planificação deverá ser concretizada a curto e longo prazo, sendo, sempre, elaborada de acordo com as crianças e a comunidade em questão. Os tópicos que venham a constar no projeto de cada instituição/sala deverão ser minuciosamente escolhidos e sustentar-se nos recursos humanos, materiais, técnicos e culturais que cada instituição possui. Defendendo o trabalho colaborativo, Malaguzzi (2001, cit. por Lino, 2007, p.112) defende que “... discutir, propor, aprofundar e apresentar ideias novas não é só um instrumento profissional, é também um dispositivo que dá sentido de pertença a uma cultura, dá valor à solidariedade interpessoal e reforça a autonomia necessária para elaborar bons projetos". Nesta linha de raciocínio, Richter e Barbosa (2010, p. 91),defendem que “(...) A criação de espaços pedagógicos, de materiais e a construção de 
ações educativas que desafiem e contribuam para o desenvolvimento das crianças exigem preparo e disponibilidade das professoras."

Partindo destes pressupostos de ReggioEmilia, defende-se que, ao planificar, o Educador Infantil deverá ter em conta as caraterísticas e interesses individuais de cada criança, situando-a no seu contexto social. Neste sentido, a planificação deverá considerar a criança enquanto ser competente e transparecer o entendimento do educador do valor educativo do conhecimento na sua vertente cultural, colaborativa e investigativa.

Nesta lógica de pedagogia participativa, as experiências são planificadas e desenhadas de acordo com as necessidades desenvolvimentais das crianças (NationalInfant\&ToddlerChildCareInitiative, 2010), ou seja, o educador conhece as caraterísticas de desenvolvimento e aprendizagem das crianças, observa e reflete sobre as experiências das crianças e sobre o que elas aprendem (Dias, Correia e Marcelino, 2013; Dias e Correia, 2012), fomentando o envolvimento e a aprendizagem ativa das crianças e co-implementando o currículo em Creche.Neste sentido, o educador elabora um plano de desenvolvimento/aprendizagem, planificando a sua ação educativa de acordo com o que conhece da criança em desenvolvimento (das suas caraterísticas motoras, cognitivas, afetivas e sociais).

Considerando a planificação como ferramenta pedagógica que o Educador Infantil se socorre para sustentar a sua ação educativa, este estudo descritivo visa i) dar a conhecer a estrutura e os objetivos formulados em 6 planificações efetuadas por 3 Educadores Infantis em exercício de funções em creches portuguesas no ano letivo 2012/2013 e ii) refletir sobre a planificação enquanto ferramenta pedagógica em contexto de Creche.

\section{Metodologia}

Participantes

Participaram neste estudo três Educadoras Infantis a trabalhar em contexto de Creche no ano letivo 2012/2013, na região centro de Portugal Continental. Duas exerciam a sua profissão em Instituições Particulares de Solidariedade Social, uma na vila da Batalha (Educadora I) e outra na cidade de Fátima (Educadora II). A Educadora III trabalhava numa instituição privada na zona 
urbana da cidade de Leiria. Á data da realização deste estudo (novembro de 2013), a Educadora I era Licenciada em Educação Pré-Escolar (Pré-Bolonha) e tinha 11 anos e 6 meses de serviço. A Educadora II era Licenciada em Educação Pré-Escolar (Pré-Bolonha) e tinha 5 anos de serviço. A Educadora III tinha o Mestrado em Educação Pré-Escolar (Pós-Bolonha) e tinha 1 ano e 5 meses de experiência profissional. As 3 Educadoras, elementos do Grupo Projeto Creche, realizaram a sua formação na Escola Superior de Educação e Ciências Sociais/Instituto Politécnico de Leiria.

Instrumentos de recolha e análise de dados

Recorrendo-se às planificações e ao registo escrito de conversas informais realizadas com as participantes, analisámos os documentos em estudo sustentando a ideia de Carmo e Ferreira (1998) quando defendem que o processo de análise documental envolve a seleção, o tratamento e a interpretação da informação existente em documentos (escritos e áudio).

Os dados das planificações foram, numa primeira fase, lidos de forma transversal e, numa segunda fase, estudados analiticamente, identificando pontos comuns e divergentes e os objetivos formulados. Os dados relativos aos objetivos foram organizados em forma de quadro e interpretados quantitativa e qualitativamente de forma descritiva.

\section{Procedimento}

Após definir o âmbito de estudo e a metodologia a seguir, houve necessidade de solicitar a colaboração das participantes e a autorização das suas instituições de pertença para utilização das planificações como instrumento de recolha de dados. Com a anuência de todos os intervenientes, procedeu-se à recolha de 6 planificações (duas por Educadora Infantil/Instituição) selecionadas de acordo com o tipo de planificação (planificação semanal) e data (ano letivo 2012/2013).

Ao longo do estudo (mês de novembro 2013) foram realizadas conversas informais com as autoras das planificações com o intuito de compreender os procedimentos de elaboração das mesmas (se eram elaboradas em equipa, se havia diretrizes institucionais para os referentes a incluir ou se havia liberdade individual para escolher a tipologia de planificação a realizar).

Recolhidos os dados, identificaram-se as planificações (PA-1: planificação 1 da Educadora A; PA-2:planificação 2 da Educadora A; PB-1: planificação 1 da Educadora B; PB-2: planificação 
2 da Educadora B; PC-1: planificação 1 da Educadora C; PC-2: planificação 2 da Educadora C) e os registos das conversas (RC-PA: registo da conversa acerca da planificação com a Educadora A; RC-PB: registo da conversa acerca da planificação com a Educadora B; RC-PC: registo da conversa acerca da planificação com a Educadora C) por Educadora/Instituição.

Organizados os dados, numa primeira fase, analisaram-se globalmente as seis planificações, tendo em conta a sua estrutura e os respetivos itens. Seguidamente, examinou-se de forma detalhada as duas planificações de cada Educadora/Instituição focando a atenção nos objetivos formulados. Após este exame individual de cada um dos documentos, releram-se os registos efetuados, procurando interligar os dados. Numa segunda fase, compararam-se os objetivos formulados nas planificações de cada Educadora/Instituição, identificando pontos em comum e pontos divergentes. Por fim, efetuou-se uma leitura crítica dos dados.

\section{Apresentação e discussão dos resultados}

Os dados recolhidos dão a conhecer, de forma descritiva, as evidências das planificações de cada Educadora/Instituição. Quantitativamente, identificam-se os objetivos por planificação de cada Educadora/Instituição.

Dados das planificações A (PA) - Educadora Infantil III

As planificações PA-1 e PA-2 pertencem a uma Educadora Infantil que trabalha numa Instituição Privada, com fins lucrativos, localizada na zona urbana de Leiria/Portugal. A PA-1 foi elaborada para o período semanal de 8 a 12 de outubro de 2012 e a PA-2 para a semana de 27 a 31 de maio de 2013.

As duas planificações são semelhantes entre si, apresentando: i) um cabeçalho com o título ("planificação semanal") e a semana a que corresponde; ii) uma tabela com 4 colunas na horizontal (com os objetivos, as atividades, as áreas de conteúdo e os recursos materiais) e 5 colunas na vertical com os dias da semana; iii) em rodapé,surge o nome da educadora e da sala correspondente (por exemplo, "sala laranja”). O seu preenchimento concretiza-se através de tópicos, procurando alinhar objetivos e atividades. 
Segundo os dados do RC-PA realizada a 18 de novembro de 2013, "a grelha ${ }^{4}$ da planificação é elaborada no início do ano [letivo] pela equipa das quatro educadoras [da instituição], após discussão entre pares acerca da melhor forma de planificar. (...) Semanalmente quem planifica (elabora as atividades) é a educadora da sala". Nesta instituição, este tipo de planificação vai sendo completada ao longo do ano letivo.

A PA-1 apresenta 7 objetivos, distribuídos por 4 dos 5 dias da semana ${ }^{5}$, todos relacionados com as áreas de conteúdo das Orientações Curriculares para a Educação Pré-Escolar (Ministério da Educação, 1997): 2 objetivos relacionados com a Área de Expressão e Comunicação - Domínio da Expressão Motora (por exemplo, desenvolver a motricidade fina ao manipular o pincel e ao pintar), 1 dirigido para Área de Expressão e Comunicação - Domínio da Expressão Musical (por exemplo, exercitar, andar depressa e devagar, andar em bicos dos pés e saltar a pés juntos conciliando com mudanças de ritmo e de som de uma música), 1 correspondente à Área de Formação Pessoal e Social (por exemplo, interagir com as restantes crianças aprendendo e atribuindo valores a comportamentos e atitudes) e 3 focados na Área de Conhecimento do Mundo (por exemplo, desenvolver o conceito dentro/ fora) (ver Quadro 1).

A PA-2 apresenta 6 objetivos, igualmente distribuídos por 4 dos $5 \operatorname{dias}^{6}$ da semana e relacionados com as áreas de conteúdo da Orientações Curriculares da Educação Pré-Escolar (Ministério da Educação, 1997): 2 objetivos relacionados com a Área de Expressão e Comunicação - Domínio da Expressão Plástica (por exemplo, desenvolver as destrezas manipulativas necessárias à confeção de pinturas), 2 dirigidos para Área de Expressão e Comunicação - Domínio da Linguagem Oral e Abordagem à Escrita (por exemplo, desenvolver e adquirir novo vocabulário) e outros 2 correspondentes à Área de Formação Pessoal e Social (por exemplo, desfrutar de novas vivências) (ver Quadro 1).

Estas duas planificações não apresentam dados da idade cronológica das crianças/tamanho do grupo nem dos recursos humanos (educadora, auxiliar de ação educativa ou outro interveniente educativo) ou físicos (sala de atividades, parque, outros recursos físicos).

\footnotetext{
$4 \quad$ Grelha, em português do Brasil, corresponde ao termo tabela.

$5 \quad$ Na coluna correspondente à segunda-feira apenas surge "música" como atividade a desenvolver, estando os restantes referentes por preencher.

6 A coluna correspondente à segunda-feira não tem qualquer informação.
} 
Quadro | - Planificações (PA- | e PA-2)

\begin{tabular}{|c|c|c|c|c|c|c|c|c|}
\hline \multirow[b]{3}{*}{ Planificação } & \multicolumn{7}{|c|}{ Objetivos } & \multirow[t]{3}{*}{ Total } \\
\hline & \multirow[b]{2}{*}{$\begin{array}{l}\text { Áre de Formaçăo } \\
\text { Pessoal e Social }\end{array}$} & \multicolumn{5}{|c|}{ Área de Expressão e Comunicação } & \multirow[b]{2}{*}{$\begin{array}{l}\text { Arrea de } \\
\text { Conhecimento } \\
\text { do Mundo }\end{array}$} & \\
\hline & & $\begin{array}{c}\text { Domínio de } \\
\text { Expresssão } \\
\text { Plástica }\end{array}$ & $\begin{array}{c}\text { Domínio de } \\
\text { Expressẫo } \\
\text { Motora }\end{array}$ & $\begin{array}{c}\text { Domínio de } \\
\text { Expressão Musical }\end{array}$ & $\begin{array}{l}\text { Domínio da } \\
\text { Matemática }\end{array}$ & \begin{tabular}{|c|} 
Domínio da \\
Linguagem \\
Oral e \\
Aborgdagem \\
à escrita
\end{tabular} & & \\
\hline PA-1 & 1 & 0 & 2 & 1 & 0 & 0 & 3 & 7 \\
\hline PA-2 & 2 & 2 & 0 & 0 & 0 & 2 & 0 & 6 \\
\hline Total & 3 & 2 & 2 & 1 & 0 & 2 & 3 & 13 \\
\hline
\end{tabular}

Em síntese, os objetivos formulados nestas duas planificações semanais da Educadora Infantil III organizaram-se de acordo com as Orientações Curriculares para a Educação Pré-Escolar (Ministério da Educação, 1997). De acordo com Vilar (1993), estas planificações traduzirão o pensamento científico e pedagógico desta Educadora/Instituição e poderão considerar-se planificações lineares (Freitas, 1995).

Pensando na realidade portuguesa e nas finalidades educativas da Creche (Portugal, 1998, 2012), questionamos a existência de uma coluna denominada "áreas de conteúdo", terminologia sustentado em normativos que se dirigem ao trabalho com crianças dos 3/6 anos (Ministério da Educação, 1997).

Dados das planificações B (PB) - Educadora Infantil I

As planificações PB-1 e PB-2 pertencem a uma Educadora Infantil que trabalha numa Instituição Particular da Segurança Social (IPSS) que fica localizada na zona urbana da Batalha/Portugal. A PB-1 foi elaborada para o período semanal de 11 a 15 de fevereiro de 2013 e a PB-2 para a semana de 15 a 19 de abril de 2013.

As duas planificações são semelhantes entre si, apresentando: i) um cabeçalho com o logotipo da Instituição (“Centro Infantil xxxxx”), da Associação a que pertence (“Associação xxxxx”) e o título ("plano semanal de atividades"); ii) uma tabela com a identificação da sala ("sala: $2 / 3$ anos"), da educadora, da auxiliar de ação educativa e do período semanal a que se destina; iii) uma segunda tabela com 3 colunas (com as atividades, os objetivos e os recursos); iv) um espaço para o preenchimento da avaliação do plano semanal; v) em rodapé, encontra-se a identificação do número de um impresso ${ }^{7}$.

$7 \quad$ Este dado leva-nos a inferir que a Instituição estará certificada pelo Ministério da Solidariedade, Emprego e Segurança Social ou em processo de Certificação e que, por isso, se apoia no Manual Processos-Chave da Creche (Instituto da Segurança Social, 20 I0). Esta ideia é corrobora- 
A PB-1 apresenta 14 objetivos, 5 direcionados para o domínio cognitivo (por exemplo, desenvolver a atenção e as capacidades de ouvir), 4 para o domínio social (por exemplo, tomar consciência de si próprio e dos outros) e 3 para o domínio motor (por exemplo, desenvolver a motricidade fina). Os restantes 2 estão relacionados com a ação da educadora e com a época do ano, o carnaval (ver Quadro 2).

A PB-2 apresenta 13 objetivos, 2 relacionados com a ação educativa da educadora (1 centrase na época do ano - primavera - e o outro refere-se às aprendizagens das crianças desenvolvidas durante as rotinas) e os restantes 11 relacionados com os domínios de desenvolvimento das crianças: 3 inserem-se no domínio cognitivo [por exemplo, fomentar a compreensão de contos infantil], 5 no domínio motor [por exemplo, desenvolver a destreza manual] e 3 no domínio social [por exemplo, fomentar a interação com os colegas/adultos]. (ver Quadro 2).

Quadro 2 - Planificações (PB-I e PB2)

\begin{tabular}{|c|c|c|c|c|c|}
\hline \multicolumn{7}{|c|}{ Objetivos } & \\
\hline Flaniificą̧ăo & $\begin{array}{c}\text { Domínio } \\
\text { Cognitivo }\end{array}$ & $\begin{array}{c}\text { Domínio } \\
\text { Motor }\end{array}$ & $\begin{array}{c}\text { Domínio } \\
\text { Social }\end{array}$ & $\begin{array}{c}\text { Dirigidos para a } \\
\text { educadora }\end{array}$ & Total \\
\hline PB-1 & 5 & 3 & 4 & 3 & 15 \\
\hline PB-2 & 3 & 5 & 3 & 2 & 13 \\
\hline Total & 8 & 8 & 7 & 5 & 28 \\
\hline
\end{tabular}

De referir que na PB-1 não se identificam as crianças como recursos humanos (ainda que se identifiquem os adultos em interação com as crianças) e na planificação PB-2, na coluna "recursos", já surgem as crianças identificadas como recursos humanos. Na PB-1, os objetivos identificam-se por tópicos, evidenciando-se uma transversalidade entre os dias da semana e as atividades, podendo-se observar uma co-relação entre estes dois itens (objetivos e atividades). Na PB-2, os objetivos aparecem alinhados com as atividades, parecendo encaixar dentro dos diferentes domínios de desenvolvimento.

Estes dados levam-nos a inferir a valorização da criança em desenvolvimento (Post \& Hohmann, 2007; Dias, Correia \& Marcelino 2013) e a perspetivar a planificação como um dispositivo de pertença a uma cultura (Lino, 2007), numa lógica de planificação linear (Freitas, 1995). 
Dados das planificações C (PC) - Educadora Infantil II

As planificações PC-1 e PC-2 pertencem a uma Educadora Infantil que trabalha numa Instituição Particular da Segurança Social (IPSS), de cariz religioso, que fica localizada na zona urbana de Fátima, "fica à saída, isto é, arredores da cidade, o que muitos pais acham um privilégio" (RC-PC). A PC-1 foi elaborada para o período semanal de 3 a 7 de dezembro de 2012 e a PC-2 para a semana de 21 a 25 de janeiro de 2013.

As duas planificações são semelhantes entre si, apresentando: i) no cabeçalho, o número do impresso e a data da edição ${ }^{8}$, a identificação do número da página, o logotipo da Instituição ("Creche xxxx"), a morada e os contatos da instituição, a identificação da planificação ("Planificação semanal das atividades") e uma tabela com 3 colunas, com a identificação da educadora, da semana e da sala ("Floresta”); ii) uma tabela com 4 colunas na horizontal (dias da semana, proposta educativa, objetivos e recursos materiais) e 5 linhas na vertical, uma para cada dia da semana. O seu preenchimento concretiza-se através de tópicos (objetivos e recursos materiais) e de forma descritiva (proposta educativa), procurando alinhar objetivos e propostas educativas.

Estas duas planificações, do tipo linear (Freitas, 1995), não apresentam informação relativa ao grupo de crianças (identificam o nome da sala, mas não mencionam a idade do grupo de crianças).

Segundo os dados do RC-PC, a planificação "foi estruturada por ambas as educadoras e pela direção [da instituição]. Na nossa instituição as educadoras planificam em conjunto para a sala do berçário e às segundas reúnem-se com as auxiliares para ajudar na planificação (ideias, sugestões). Para a sala $1 / 2$ anos e 2/3 anos o processo é idêntico, as educadoras reúnem-se e planificam (o que muda são os objetivos)". Este dado parece corroborar a ideia de Richter e Barbosa (2010) quando defendem que a construção de ações educativas exigem disponibilidade dos docentes.

A PC-1 apresenta 21 objetivos, distribuídos ao longo dos 5 dias da semana:

a) Segunda-feira: 2 objetivos do domínio motor (por exemplo, desenvolver a motricidade fina), 1 objetivo do domínio cognitivo (por exemplo, desenvolver a criatividade) e 1 objetivo do domínio social (por exemplo, desenvolver a sensibilidade e o respeito pelo outro);

b) Terça-feira e quarta-feira:4 objetivos do domínio motor e 4 do domínio cognitivo;

8 Parâmetros da certificação da qualidade e do Manual Processos-Chave da Creche - Instituto da Segurança Social (20 I0). 
c) Quinta-feira: 5 objetivos do domínio cognitivos;

d) Sexta-feira: 2 objetivos do domínio social e 2 objetivos no domínio cognitivo.

No total, identificámos 12 objetivos relacionados com o domínio cognitivo, 6 objetivos arrolados ao domínio motor e 3 objetivos ao domínio social (ver Quadro 3), todos focalizados no desenvolvimento da criança.

A PC-2 apresenta 20 objetivos, igualmente distribuídos ao longo dos 5 dias da semana:

a) Segunda-feira: 2 objetivos relacionados com o domínio motor e 2 objetivos com o domínio cognitivo

b) Terça-feira: 2 objetivos relacionados com o domínio social e 2 com o domínio cognitivo;

c) Quarta-feira: 2 objetivos relacionados com o domínio cognitivo e 2 com o domínio motor;

d) Quinta-feira: 3 objetivos relacionados com domínio cognitivo e 1 com o domínio social;

e) Sexta-feira: 1 objetivo relacionado com o domínio social, 2 com o domínio motor e 1 com o domínio cognitivo.

No total, identificámos 10 objetivos relacionados com o domínio cognitivo (por exemplo, desenvolver os sentidos), 6 com o domínio motor (por exemplo, desenvolver a motricidade global e fina) e 4 com o domínio social (por exemplo, desenvolver atitudes de partilha), todos focalizados no desenvolvimento da criança (ver Quadro 3).

De referir que, embora as propostas educativas identificadas nestas duas planificações assumam um cariz religioso, o domínio de desenvolvimento afetivo e social não é o mais referido. Situando estas planificações numa Instituição de cariz religioso, compreendemos a sua elaboração de acordo com as crianças e a comunidade em questão (Lino, 2007), numa lógica de gestão flexível do currículo (Portugal, 1998; Formosinho, 1996). 
Quadro 3 - Planificações (PC-I e PC-2)

\begin{tabular}{|c|c|c|c|c|}
\hline \multicolumn{4}{|c|}{ Objetivos } & \multirow[b]{2}{*}{ Total } \\
\hline Planificação & $\begin{array}{l}\text { Domínio } \\
\text { Cognitivo }\end{array}$ & $\begin{array}{l}\text { Domínio } \\
\text { Motor }\end{array}$ & $\begin{array}{c}\text { Domínio } \\
\text { Social }\end{array}$ & \\
\hline PC-1 & 12 & 6 & 3 & 21 \\
\hline PC-2 & 10 & 6 & 4 & 20 \\
\hline Total & 22 & 12 & 7 & 41 \\
\hline
\end{tabular}

Após o estudo das planificações por Educadora/Instituição, procurámos comparar os dados das 6 planificações ao nível da quantidade de objetivos, atividades/propostas e recursos, conforme Quadro 4.

Quadro 4 - Quantidade de objetivos, atividades/propostas e recursos nas 6 planificações

\begin{tabular}{|c|c|c|c|c|c|}
\hline \multicolumn{2}{|c|}{ Planificações } & $\begin{array}{c}\text { N.@ de } \\
\text { objetivos }\end{array}$ & $\begin{array}{c}\text { N.@ de } \\
\text { atividades/pro } \\
\text { postas }\end{array}$ & $\begin{array}{c}\text { N. } \text { de } \\
\text { recursos }\end{array}$ & Total \\
\hline \multirow{2}{*}{ PA } & PA-1 & 4 & 5 & 12 & 21 \\
\cline { 2 - 7 } & PA-2 & 6 & 5 & 5 & 16 \\
\hline \multirow{2}{*}{ PB } & PB-1 & 11 & 14 & 14 & 39 \\
\cline { 2 - 7 } & PB-2 & 11 & 8 & 15 & 34 \\
\hline \multirow{2}{*}{ PC } & PC-1 & 21 & 5 & 16 & 42 \\
\cline { 2 - 7 } & PC-2 & 20 & 5 & 10 & 35 \\
\hline \multicolumn{2}{|l}{ Total } & 73 & 42 & 72 & 187 \\
\hline
\end{tabular}

Conforme os dados do Quadro 4, a planificação com mais objetivos (21) foi a PC-1 e a que apresentou menos foi a PA-1 (4). As restantes planificações apresentaram 6 objetivos (PA-2), 11 objetivos (PB-1 e PB-2) e 20 objetivos (PC-2).

Na PB-1 encontra-se o maior número de atividades/propostas (14), sendo seguida pela PB-2 com 8 atividades/propostas. As restantes planificações apresentaram 5 atividades/propostas, cada.

A planificação que mais recursos identifica é PC-1 (16) e a que menos os refere é a PA-2 (5). As restantes planificações referem 10 recursos (PC-2), 12 (PA-1), 14 (PB-1) e 15 (PB-2).

Analisando os dados por Educadora/Instituição, verificamos que as planificações A, da Educadora Infantil III identificam, no seu total, 10 objetivos, 10 atividades/propostas e 17 recursos. As planificações B, da Educadora Infantil I, 22 objetivos, 22 atividades/propostas e 29 recursos e as planificações C, Educadora Infantil II, 41 objetivos, 10 atividades/propostas e 26 recursos. 
As planificações A e C apresentam o mesmo número de atividades/propostas (10), número inferior à das planificações B (22). O número de objetivos diverge nas três planificações, oscilando entre 10 (PA), 22 (PB) e 41 (PC). O número de recursos confirma as diferenças nas três tipologias de planificação (17 para a PA, 29 para a PB e 26 para a PC). Face a estes dados, podemos inferir que o número total de objetivos, de atividades/propostas e de recursos são variáveis nestas planificações, confirmando a necessidade de uma gestão flexível do currículo (Portugal, 1998; Formosinho, 1996).

As planificações da Educadora I (PB-1 e PB-2) identificam um espaço para a avaliação do plano semanal, dado valorizado por Post e Hohmann (2007) e Simões (2004), quando defendem que a avaliação deverá fazer parte do trabalho do educador que quer conhecer e responder às necessidades e interesses de cada criança e do grupo.

As planificações das Educadoras II (PC1-1 e PC-2) e III (PA-1 e PA-2) não identificam o grupo de crianças/idade(s) cronológica(s) ao qual se destinam e a Educadora I, na PB-2, inclui o grupo de crianças nos recursos humanos (ao contrário da PB-1). Concordando com Vilar (1993), quando defende que planificar é colocar em ação, numa determinada realidade, as crianças com que se trabalha, defendemos que será importante identificar o grupo de crianças na planificação.

Estes documentos analisados representarão planos de desenvolvimento/aprendizagem das crianças (Portugal, 2012), realçarão as reflexões de quem planifica (Dias, 2009) e procurarão ajustarse aos contextos de ação, valorizando a criança e as suas especificidades (Dias, Correia \& Marcelino, 2013; Dias \& Correia, 2012; National Infant \& Toddler Child Care Initiative). Neste sentido, poderão assumir-se como instrumentos que otimizam a prática educativa (Pacheco, 1990; Vilar, 1993) e que refletem as ideias, os valores e a cultura de todos os que nela laboram (Lino, 2007).

\section{Conclusão}

Este estudo apresentou 6 planificações efetuadas por Educadoras Infantis em exercício de funções em Creches portuguesas no ano letivo 2012/2013. Descrevendo a(s) estrutura(s) das planificações em estudo, identificou-se a organização e tipologia de objetivos apresentados e refletiu-se sobre a planificação enquanto ferramenta pedagógica.

Os dados levantados levam-nos a afirmar que, em termos de estrutura, as planificações assumem um aspeto comum (todas surgem em forma de grelha), integrando o pensamento e a ação de 
cada uma das educadoras (Zabalza, 1992). No que respeita à organização, todas estão organizadas por objetivos, numa lógica de planificação linear, modelo clássico que se carateriza por uma conotação behaviorista de aprendizagem (Freitas, 1995).

Em termos de denominação, as planificações surgem identificadas de forma diferente: "Planificação Semanal" (PA); "Plano Semanal de Atividades" (PB) e "Planificação Semanal de Atividades" (PC) o que nos leva a inferir que, independentemente da terminologia adotada, o Educador Infantil recorre à planificação para otimizar a sua prática educativa, adaptando-a à sua realidade educativa, ao seu grupo de crianças, numa procura de integração teórica da sua prática (Vilar, 1993).

\section{Referências}

CARMO, Hermano e FERREIRA, Manuela. Metodologia da Investigaçáo. Lisboa: Universidade Aberta,1998.

DIAS, Isabel. Promoçáo de competências em educação. Leiria: Instituto Politécnico de Leiria e Instituto de Investigação, Desenvolvimento e Estudos Avançados.

DIAS, Isabel; CORREIA, Sónia e MARCELINO, Patrícia. Desenvolvimento na primeira infância: características valorizadas pelos futuros educadores de infância. Revista Eletrónica de Educaçáo, v.7, n.o 3, pp. 9-24, 2013.

DIAS, Isabel e CORREIA, Sónia. Processos de aprendizagem dos 0 aos 3 anos: contributos do sócio-construtivismo. Revista Iberoamericana de Educaçáo, n. ${ }^{\circ}$ 60/1, pp. 1- 10, 2012.

FORMOSINHO, Júlia (org.). Modelos Curriculares para a Educação de Infância. Porto: Porto Editora, 1996.

FREITAS, Mário. A planificaçáo do ensino das Ciências: uma perspectiva de mudança conceptual. Braga: Departamento de Educação do Instituto da Universidade do Minho, 1995.

INSTITUTO DA SEGURANÇA SOCIAL (Ed.). Manual de Processos- Chave Creche. Lisboa: Ministério da Segurança Social, 2010.

LINO, Dalila. O Projecto de Reggio Emília. In: Oliveira-Formosinho, J. (Org). Modelos Curriculares para a Educaçáo de Infância - Construindo uma práxis de participaçáo. 3.a ed. Porto: Porto Editora, 2007. pp. 93-121.

MINISTÉRIO DA EDUCAÇÃO. Orientaçóes Curriculares para a Educação Pré-Escolar. Lisboa: Departamento da Educação Básica - Núcleo da Educação Pré-Escolar. Ministério da Educação, 1997.

NATIONAL INFANT\& TODDLER CHILD CARE INITIATIVE. Infant/toddler curriculum and individualization. EUA: National Training Institute for Child care Health Consultants, 2010.

PORTUGAL, Gabriela. Crianças, famílias e creches - uma abordagem ecológica da adaptaçáo do bebé à creche. Porto: Porto Editora, 1998. 
PORTUGAL, Gabriela. Finalidades e práticas educativas em creche - das relaçóes, actividades e organizaçáo dos espaços ao currículo em creche. Porto: CNIS, 2012.

POST, Jaclyn e HOHMANN, Mary. Educação de bebés em infantários - cuidados e primeiras aprendizagens. Lisboa: Fundação Calouste Gulbenkian, 2007.

PACHECO, José. Planificaçáo Didáctica: uma abordagem prática. Braga: Centro de Estudos Educacionais e Desenvolvimento Comunitário-Universidade do Minho, 1990.

QUIVY, Raymond. e CAMPENHOUDT, Luc. Manual de Investigação em Ciências Sociais. Lisboa: Gradiva, 1992.

RICHTER, Sandra e BARBOSA, Maria.Os bebes interrogam o currículo: as múltiplas linguagens na creche. Santa Cruz do Sul: Universidade de Santa Cruz do Sul, 2010.

SIMÓES, Ana. O educador como prático reflexivo ... e a construção da sua identidade pessoal. Cadernos de Educaçáo Infantil, pp. 8-13, 2004.

VILAR, António. O professor planificador. Porto: Edições ASA, 1993.

ZABALZA, Miguel. Planificaçáo e Desenvolvimento Curricular na Escola. Rio Tinto: Ediçôes Asa, 1992. 